\title{
Problemas do consórcio Realismo Crítico / Análise do Discurso Crítica para a análise social do discurso: sociopolitizando a postura crítica
}

\section{Some problems from consortium Critical Realism / Critical Discourse Analysis for the social analysis of discourse: social- politicizing the critical posture}

Claudiana Nogueira de Alencar

Universidade Estadual do Ceará (UECE), Fortaleza, Ceará, Brasil.

claunoce@gmail.com

Emanoel Pedro Martins Gomes

Universidade Estadual do Ceará (UECE), Fortaleza, Ceará, Brasil emanoelpmg@hotmail.com

Resumo: Este trabalho tem como objetivo destacar alguns problemas da postura de analistas do discurso que tomam a explanação teórica de um discurso como desmistificadora da impressão empírica que este nos oferece. Entendemos que tal postura se torna problemática, sobretudo quando decorre de uma ênfase exagerada de aspectos do Realismo Crítico de Roy Bhaskar, que fundamenta a Análise do Discurso Crítica de Norman Fairclough. Para explicá-la, desenhamos um panorama geral do Realismo Crítico, destacando os pressupostos compartilhados pela ADC e discutindo os problemas desse consórcio para a análise social. Com a discussão, entendemos que o que quer que venham a ser a compreensão e explanação que tenhamos acerca dos fenômenos discursivo-sociais, até mesmo de suas conexões causais, teremos sempre um ato discursivo, 
com seus valores sociais, políticos e ideológicos; o critério causal se torna apenas uma forma científica de argumentar a possível eficácia das explicações dos eventos sociais.

Palavras-chave: Análise do Discurso Crítica; Realismo Crítico; Linguística Aplicada.

\begin{abstract}
This paper aims to highlight some problems from the posture of discourse analysts who take the theoretical explanation of a discourse as demystifying the empirical impression it offers us. We understand that this posture becomes problematic especially when it stems from an overemphasis of aspects of Critical Realism by Roy Bhaskar, which grounds the Critical Discourse Analysis by Norman Fairclough. In order to explain it, we draw an overview of Critical Realism by detaching the presuppositions shared by CDA and discussing the problems of this consortium for social analysis. With the discussion, we understand that whatever may be the understanding and explanation we have about social discursive phenomena, even their causal connections, we will always have a discursive act, with its social, political and ideological values; the causal criterion becomes just a scientific way of arguing the possible effectiveness of the explanations of social events.
\end{abstract}

Keywords: critical discourse analysis; critical realism; applied linguistics.

Recebido em 17 de julho de 2014. Aprovado em 31 de outubro de 2014.

\title{
1 Situando o ponto de partida
}

A pedra de esteio teórica e epistemológica de nossa discussão vem das reflexões de dois principais pensadores da "virada pragmática" na

\footnotetext{
${ }^{1}$ A expressão "virada pragmática" deve ser entendida no quadro de discussões filosóficas que, desde o século 19, concedem um papel mais central à linguagem na formulação do conhecimento humano. De certa forma, essa mudança de paradigma na filosofia, que, na esteira do pensamento grego socrático, preocupava-se essencialmente com
} 
filosofia da linguagem: Ludwig Wittgenstein e John Austin. Na obra de cada um, Investigações Filosóficas (WITTGENSTEIN, 1999) e Quando Dizer é Fazer (AUSTIN, 1990, 1975), encontramos as ideias principais e basilares do que respectivamente se chama de antiessencialismo e performatividade em linguagem.

Wittgenstein, com suas investigações, desmantela um dos fundamentos mais notórios do pensamento ocidental acerca da linguagem, qual seja: o de que a linguagem tem como função representar, figurar a realidade, tal como, num primeiro momento de seus trabalhos, ele mesmo acreditava (cf. OLIVEIRA, 2006). A filosofia da linguagem, até então, baseava-se na assunção de que ela, a linguagem, tinha como função retratar ou representar o mundo. E a tarefa da filosofia era clarificar, depurar a linguagem para que ela viesse a realizar essa função satisfatoriamente. Essa concepção partia de pressupostos formulados pela "virada linguística", para a qual qualquer conhecimento que pudéssemos ter acerca do mundo passava antes pelas estruturas da linguagem. Esse paradigma filosófico, utilizando-se de noções lógicas para empreender suas análises, partia sempre da investigação de proposições, centrando-se

questões de ordem ontológica, pode ainda ser remontada na modernidade às reflexões de Immanuel Kant, no século 18, quando a metodologia filosófica, em vez de lançar as perguntas sobre a ontologia (o real das coisas), decide se questionar sobre as condições de possiblidade de se conhecer verdadeiramente o mundo. Nesse caso, no quadro da filosofia, encontramos uma mudança da ordem da ontologia para a ordem da epistemologia, dentro da qual vai se inserir a preocupação com o papel da linguagem na constituição do conhecimento humano. A filosofia analítica, inaugurada por Gottlob Frege (1978) e continuada por outros representantes, como George Moore, Bertrand Russel, Rudolf Carnap e o jovem Ludwig Wittgenstein (com seu Tractatus LogicoPhilosophicus), surge como um paradigma filosófico-metodológico que coloca a linguagem no centro das discussões, afastando-a de uma tendência psicologizante na filosofia de então. Com esse paradigma, assistimos à "virada linguística" no campo da filosofia. A virada pragmática se dará somente a partir da década de 1940, notadamente com a reviravolta na filosofia analítica iniciada pelo trabalho tardio de Wittgenstein (Investigações Filosóficas) e prosseguida por filósofos de Oxford (como John Langshaw Austin, Gilbert Ryle e Peter Strawson). Nela, a preocupação passa, em vez de uma consideração baseada na lógica e na matemática, para uma atenção com a linguagem em situações ordinárias de uso. Se a virada linguística está vinculada ao surgimento da filosofia analítica, a virada pragmática concerne às discussões tardias daquela em torno da linguagem ordinária. Para essa discussão, cf. Oliveira (2006) e Rorty (1992). 
na correlação entre linguagem e mundo, para estabelecer critérios que permitissem dizer quando uma proposição realizava a contento sua tarefa de referir a estados de coisas no mundo.

Wittgenstein (1999) rechaça essa compreensão. A ideia de que a linguagem é uma afiguração, uma representação, uma "re-apresentação" de uma apresentação primeira - a do mundo à consciência - (de que as proposições se constituem de um modo pelo qual sua verdade ou falsidade é veritativa, depende da correspondência com um estado de coisas no mundo; e de que a estrutura da linguagem logicamente perfeita espelha a estrutura da realidade), recaí, nas reflexões de Wittgenstein, sobre a crença filosófica de que todos os usos possíveis da linguagem têm por única função reportar-se a objetos. Segundo ele: “[...] esse sistema [em que se acredita ser a essência da linguagem humana denominar coisas] não é tudo aquilo que chamamos de linguagem" (WITTGENSTEIN, 1999, § 3, p. 28). Para o filósofo, esse sistema de referências é, na verdade, um tipo de jogo de linguagem, entre inúmeros outros.

A noção de "jogos de linguagem" como marca da linguagem humana nos faz questionar um dos pressupostos da Análise de Discurso Crítica (doravante ADC) - aparato teórico-metodológico sobre o qual iremos refletir: a afirmação de que a linguagem é apenas um elemento das práticas sociais e de que ela pode internalizar ou não outros elementos, "não linguísticos". Com a noção de "jogos de linguagem", contudo, Wittgenstein (1999) não deslinda a fronteira do que é linguístico e do que não é linguístico, como podemos ver em vários momentos de suas investigações:

o termo "jogo de linguagem" deve aqui salientar que o falar da linguagem é uma parte de uma atividade ou de uma forma de vida (§ 23, p. 35);

Chamarei também de "jogos de linguagem" o conjunto da linguagem e das atividades com as quais está interligada (§ 7, p. 30); e

"Ligando a barra com a alavanca, faço funcionar o freio." - Sim, dado todo o mecanismo restante. Apenas com este, é alavanca de freio; e, separada do seu objeto, nunca é alavanca, mas pode ser qualquer coisa ou nada ( $(6$, p. 29$)$. 
Dessa forma, o que é linguístico e o que não seria considerado linguístico, em muitas situações, comporiam uma mesma atividade, constituiriam uma mesma ação, devendo, portanto, ser considerados em conjunto, sobretudo se estiverem interligados.

Por seu turno, a performatividade, proveniente das reflexões de Austin (1990, 1975), pode ser considerada como uma ideia ainda mais radical para o trato com a linguagem. Radical porque Austin fornece a possibilidade de pensarmos a linguagem como uma ação. Ele concebe a linguagem como uma forma de ação, ao dizer (quase na esteira de Wittgenstein a respeito dos jogos de linguagem como forma de vida) que não há como dizermos quando um proferimento é constatativo ou performativo, ou seja, uma constatação - um referir-se a estado de coisas no mundo - ou uma performance, uma ação - um ato de fala, que age sobre o mundo. Austin, assim como Wittgenstein, parte do entendimento de que o problema da filosofia analítica estava em acreditar na existência de enunciados que pudessem somente descrever estados de coisas no mundo, o que permitiria, assim, conceder-lhes valores como verdadeiro ou falso, ao ser verificada a correspondência entre o que declarava o enunciado e as coisas que ele designaria.

Assim, Austin nos fornece uma visão de que a linguagem não descreve coisas do mundo, mas, antes, age sobre o mundo e sobre as pessoas. $\mathrm{O}$ ato perlocucionário (aquilo que poderia ser considerado como uma das dimensões dessa ação que é o linguajar) deixa entrever uma importante contribuição. Ele afirma que é preciso distinguir três consequências suas: a primeira seria que todo ato perlocucionário envolve "assegurar a apreensão" (no original, 'securing uptake', cf. AUSTIN, 1975, p. 138) de significado de um ato de fala; a segunda é que ele tem resultados; e, por fim, ele leva a uma resposta ou sequela. Com a noção de uptake, resgatada por Paulo Ottoni (1998), percebemos que todo uso da linguagem se dá numa relação entre interlocutores, e, o que é mais relevante, que não há regras ou critérios formalistas definitivos que venham a definir a significação. O uptake, portanto, é uma condição necessária do próprio ato (de fala) para que ele venha a ter um sentido; ou, como argumenta Ottoni (1998, p. 85), "na proposta austiniana, a intenção [e, por conseguinte, a significação] não pertence somente ao sujeito falante que a transmite, mas é garantida, via uptake, pelo sujeito ouvinte para assegurar sua apreensão". Assim, temos o fato de que as consequências de um ato de linguagem, ou melhor, seus significados não 
são previamente determinados, adquirindo sentido, apenas, no contexto da enunciação, na interação; é somente quando nosso interlocutor reage ao nosso ato de fala que podemos verificar que sentido, que significado, esse ato adquiriu.

Essas reflexões são importantes, visto que nos colocam no centro do processo de constituição de uma realidade que pesquisamos. Wittgenstein e Austin nos lançam a responsabilidade de que o que fazemos com a linguagem, em qualquer um de seus tratamentos, nos jogos que jogamos com a linguagem, é uma ação sobre o mundo, uma ação de construção do mundo, despojando-nos de um possível uso instrumental, representacionista, essencialista da linguagem, como se depreenderá, nas seções seguintes, da crença de a pesquisa social ser uma "ciência profunda", que vasculha conexões causais que nos levariam a uma dimensão intransitiva dos fenômenos investigados. Essa crença encontra-se, por exemplo, em uma teoria frequentemente utilizada na área da Linguística Aplicada, a ADC. Seu problema reside justamente na postura crítica do pesquisador que dela faz uso e se reflete quando se toma a explanação teórica de um discurso como desmistificadora da sua impressão empírica. Com base nos dois filósofos acima, entretanto, percebemos que a linguagem é compulsória e inescapável, e, sendo assim, é uma construção social que promovemos ao linguajarmos e de que jamais conseguimos nos furtar, o que reforça a necessidade de um trato mais crítico no que concerne à pesquisa social e linguística sobre o discurso.

\section{Problemas do consórcio análise do discurso crítica/realismo crítico}

A Teoria Social do Discurso ou Análise do Discurso Crítica (ADC) ou ainda Abordagem Dialético-Relacional, desenvolvida pelo linguista britânico Norman Fairclough, é uma referência importante na seara acadêmica, e disso não se tem dúvidas, pois encontramos cada vez mais pesquisadores que por ela se interessam em pesquisas que não se restringem à área de Letras e Linguística, mas que brotam também em toda a dimensão das ciências humanas e sociais. Tal teoria oferece uma abordagem inovadora para a análise social dos discursos e confere ao discurso um papel relevante nas práticas sociais ao reunir uma análise linguisticamente orientada e o pensamento social crítico (útil para a compreensão da linguagem nessa nova conjuntura) num quadro analítico adequado à pesquisa científica social. Por conta disso, é comum 
escutarmos sobre a capacidade de "empoderamento" ('empowerment') que, frequentemente, atribuem à ADC (CAMERON et al., 1992; BLOMMAERT, 2005).

Mas, até que ponto tal capacidade não residiria em que a ADC opere com um vocabulário explanatório realista que permite as afirmações feitas com base nele serem respaldadas por um valor de verdade, científico, tão à altura de uma verdadeira ciência (no sentido que tradicionalmente se deu a esse termo)? Tal inquietação está presente, por exemplo, quando nas análises sócio-discursivas que tomam como referencial teórico-metodológico o quadro elaborado por Lilie Chouliaraki e Norman Fairclough (1999) e retomado por Norman Fairclough (2003), no qual a ADC concede uma postura desmistificadora dos textos, já que o valor epistêmico dado ao seu modo de explanação a põe num lugar sobrepujante em relação a qualquer outra explicação que possa tratar de um evento discursivo. O quadro analítico da $\mathrm{ADC}^{2}$ fornece, por isso, um novo prisma (o da análise crítica e cientifica do pesquisador), com a explicação do que, de fato, ocorreria ou do que é o caso.

Contudo, tal posicionamento analítico frente aos eventos pesquisados parece incorrer em deslizes que a Linguística Aplicada hoje (cf. PENNYCOOK, 2001; MOITA LOPES, 2006) vem tendo o cuidado de não cometer: a construção de certezas ao formular explicações definitivas que pareçam acenar com o privilégio de uma visão mais clara e profunda dos fenômenos sociais (cf. também as ressalvas de FABRÍCIO, 2006). A postura frequente (porém implicitamente) assumida em análises do discurso críticas - a de que a explanação científico-teórica do objeto pesquisado em questão deve ser tomada como desmistificadora da sua impressão empírica comum que ele nos oferece - carrega certos problemas sociais e políticos que afetariam diretamente a pesquisa e a relevância social do analista, uma vez que a forma como o resultado da pesquisa é apresentado implica a ideia de que o conhecimento atingido

\footnotetext{
${ }^{2}$ Aqui, ao citarmos o quadro analítico da $\mathrm{ADC}$, iremos nos referir especificamente à proposta teórico-metodológica desenvolvida por Fairclough em conjunto com Lilie Chouliaraki na obra Discourse in Late Modernity: Rethinking Critical Discourse Analysis (1999), que se estende ao seu livro individual Analysing Discourse: Textual Analysis for Social Research, de 2003. Tal delimitação é imprescindível, pois, além de considerarmos tais obras outro rumo que o autor imprimiu à sua teoria, ela não permitirá estender nossos questionamentos a etapas promissoras de sua proposta teórica, como a de Discourse and Social Change, de 1992 (FAIRCLOUGH, 2001).
} 
tem status privilegiado, por ter calcado um caminho mais "profundo" e inabitual no assunto sobre o qual a pesquisa versa(va). Em outras palavras, a pesquisa em ADC teria conseguido, assim, ir mais longe do que comumente se pensa(va) em relação a um tema, o que lhe concede um status científico, autorizado, ao fornecer uma compreensão inovadora, como se vê a seguir:

Seguindo Bhaskar (COLLIER, 1994), vemos que a ciência social crítica tem tanto um objeto 'transitivo' quanto 'intransitivo'. Seu objeto intransitivo são as práticas reais que ela está analisando. Seu objeto transitivo são as prototeorias que são produzidas como parte dessas práticas - o elemento reflexivo dessas práticas. Em termos de seu objeto transitivo, a teoria crítica se propõe a transformar prototeorias em teorias cientificas por meio de uma aplicação da lógica dialética [...]. Na medida em que prototeorias funcionam ideologicamente, como mostradas através da análise crítica - por auxiliarem práticas a sustentarem relações de dominação -, a ciência social crítica deve subverter as práticas que ela analisa, mostrando prototeorias como sendo más percepções e produzindo teorias cientificas que podem ser tomadas (e encetar lutas) dentro das práticas (CHOULIARAKI; FAIRCLOUGH, 1999, p. 32-33, grifos nossos). ${ }^{3}$

Não obstante, Fairclough (2003) é muito consciente do papel que o pesquisador em ADC tem de ter diante dos fenômenos sobre os quais se debruça e de como se deve comportar frente a eles. Sabe

\footnotetext{
${ }^{3}$ No original: "Following Bhaskar (Collier, 1994), we see critical social science as having a 'transitive' as well as an 'intransitive' object. Its intransitive object is the actual practices it is analyzing. Its transitive object is the proto-theories which are produced as a part of those practices - the reflexive element of practices. In terms of its transitive object, critical theory sets out to transform proto-theories into scientific theories through applying the dialectical logic [...]. In so far as proto-theories are shown through critical analysis to be working ideologically - to be helping the practices sustain relations of domination - critical social science may subvert the practices it analyses, by showing proto-theories to be miscognition, and producing scientific theories which may be taken up within (and enter struggles within) the practices" (CHOULIARAKI; FAIRCLOUGH, 1999, p. 32-33).
} 
que os sentidos de um texto decorrem, especialmente, do processo de construção de sentido do qual faz parte a interpretação do pesquisador. Daí ele alertar que o que somos capazes de ver da realidade de um texto depende da perspectiva que nós o abordamos, incluindo as questões sociais particulares em foco na análise e a teoria social e discursiva que se assume nessa tarefa (FAIRCLOUGH, 2003, p. 16). Assim, tal postura analítica em ADC, desmistificadora dos eventos sociais, vem do consórcio com a filosofia das ciências de Roy Bhaskar, conhecida como Realismo Crítico (doravante RC) ou Realismo Transcendental. Que problemas a filiação da ADC ao RC traria para a conduta em pesquisa social crítica, ao operar, ao mesmo tempo, com uma explanação que objetiva "alcançar níveis mais profundos da realidade em pesquisas sobre problemas sociais" (RAMALHO, 2009, p. 1), e ao defender que os sentidos de um texto provêm de um processo interpretativo em que são construídos, circunstanciados pela posição social do pesquisador? Vejamos a observação de Chouliaraki e Fairclough (1999, p. 30, grifo nosso):

\begin{abstract}
Usando criativamente tanto [a forma de produção do conhecimento como a de] a fenomenologia quanto o objetivismo, a prática teórica crítica reconhece que a ciência social tem uma base hermenêutica (ela precisa fundamentar-se nas práticas simbólicas do mundo), mas não deve se limitar a isso (ela também precisa ser uma 'ciência profunda'dos mecanismos gerativos que tornam essas práticas possíveis [...] $)^{4}$.
\end{abstract}

Boa parte dos problemas que tal filiação fornece aos pesquisadores em ADC (como a crença de que a análise crítica do discurso nos leva a ver o que realmente acontece ou que está em jogo numa prática discursiva; o compromisso de fornecer uma explicação mais científica do que outras; a ideia de que é possível chegarmos aos mecanismos gerativos de práticas e eventos sociais, ou seja, à realidade primeira dos eventos e discursos,

\footnotetext{
${ }^{4}$ No original: "Drawing creatively on both phenomenology and objectivism, critical theoretical practice recognizes that social science has a hermeneutic basis (it needs to ground itself in the symbolic practices of the world) but cannot be limited to that (it also needs to be a 'depth science' of the generative mechanisms that make these practices possible [...])" (CHOULIARAKI; FAIRCLOUGH, 1999, p. 30).
} 
entre outros) vem de um comprometimento que, se não exagera, compactua com aspectos do realismo crítico ou transcendental de Roy Bhaskar. Na seção a seguir, veremos rapidamente como se caracteriza o realismo bhaskariano.

\section{0 realismo crítico ou transcendental de Roy Bhaskar}

Sabe-se que, por realismo, quer-se dizer, em filosofia, a ideia de que há algo no mundo que existe independentemente de nós ou do que pensemos sobre ele, ideia essa que se contrapõe à visão idealista de subordinação da realidade externa à mente (a nossa mente - como num idealismo cru - ou a de Deus - como na filosofia de Berkeley) ou ao pensamento (conceitual, objetivo e racional - como na filosofia de Hegel). A despeito de suas inúmeras facetas (seja um realismo ingênuo, perceptivo, predicativo, ou científico, cf. BHASKAR, 1996), de acordo com Andrew Collier (1994, p. 6), há elementos que podem ser considerados como caracterizadores do realismo e que, de alguma forma, estão presentes na concepção realista transcendental de Bhaskar, a saber:

a) objetividade, pelo que se diz que há algo que é real, mesmo que não venhamos a conhecê-lo;

b) falibilidade ou falsibilidade ('falibility'), pelo que se diz que aquilo que se apresenta aparentemente como dado pode ser refutado por informações que ultrapassam o limite do dado;

c) transfenomenalidade ('transfactuality'), um "além das aparências", pelo que se admite que o conhecimento pode se referir não só ao fenômeno, mas também a estruturas mais profundas que podem gerá-lo ou torná-lo possível (donde podemos tirar a questão da causação ou causalidade em Bhaskar, como veremos mais adiante);

d) contrafenomenalidade, pelo que o conhecimento, ao atingir por meio da transfenomenalidade as estruturas subjacentes, pode contradizer o conhecimento das aparências.

São dessas premissas que podemos retirar, por exemplo, o caráter crítico fundamental para a argumentação da $\mathrm{ADC}$ em relação às práticas sociais que analisa e pesquisa quando seu quadro teórico-metodológico é usado. São nessas premissas - que caracterizam o fazer pesquisa com o $\mathrm{RC}$ como pano de fundo ontoepistemológico - que a ADC retira a ideia 
de uma ciência social "profunda", que procura deslindar a interseção cada vez mais complexa e profunda dos mecanismos gerativos provenientes dos estratos envolvidos em um evento social.

Em todas essas características, o que perdura é a questão fundamental da existência de uma realidade exterior e independente do ser das coisas, ou seja, é a ratificação da dimensão ontológica e transcendente do real, cujo conhecimento Bhaskar vai chamar de dimensão intransitiva do conhecimento. Contudo, como assegurar essa dimensão intransitiva do conhecimento frente às revoluções ou desenvolvimentos científicos, que foram a pedra angular de discussões de, por exemplo, Karl Popper, Thomas Kuhn e Paul Feyerabend? Para sustentar essa dimensão intransitiva face a relatividade ou falibilidade de nosso conhecimento, Bhaskar (2008) a relaciona a outra, à dimensão transitiva (ou epistemológica, imanente), que é mutável, contingente, falível, afirmando que, se há explicações alternativas do mesmo mundo e se uma teoria pode explicar mais significativamente fenômenos em termos de suas descrições do que das de outra, então existe um critério racional para se escolher entre elas. Dessa forma, Bhaskar, ao evitar um relativismo excessivo ou uma falácia epistemológica (que, a seu ver, reside em acreditar tão somente que a dimensão transitiva é a única que podemos alcançar), combina e concilia realismo ontológico, relativismo epistemológico e "racionalismo de julgamento" (no original, "judgemental rationalism', critério graças ao qual racionalmente se fazem as escolhas epistemológicas mais adequadas, cf. BHASKAR, 2008, p. xix).

Central, portanto, para se compreender essa filosofia bhaskariana, é a distinção entre três domínios da realidade (o real, o realizado 'actual', em inglês - e o empírico), além da assunção de uma ontologia estratificada do mundo, segundo a qual este seria um sistema aberto, formado por diferentes estratos (físico, químico, biológico, semiótico etc.) que funcionam de forma simultânea e que possuem estruturas gerativas e poderes causais, acarretando (tanto por o mundo ser um sistema aberto quanto por esses estratos operarem concomitantemente) efeitos imprevisíveis em forma de eventos (BHASKAR, 2005, 2008, 2009; ARCHER, 2004; COLLIER, 1994). O "real" inclui os mecanismos, processos e estruturas subjacentes que têm poderes causais e que podem ou não tanto horizontalmente ser percebidos, realizados, ativados como verticalmente ser descobertos pelo processo de desenvolvimento científico. O "realizado" ('actual'), por sua vez, refere-se ao que acontece 
se e quando esses mecanismos e estruturas têm seus poderes ativados, incluindo eventos que podem ser observados ou não. Isso implica que o que acontece não é necessariamente da forma como se percebe. Por fim, o "empírico" é o domínio acessado por nossas experiências, sendo aquilo que se sabe ter acontecido a partir de nossas observações diretas.

O que se depreende disso é que o elemento transcendental de sua filosofia vai se encaixar justamente na ideia ontológica fundamental de algo a priori, a despeito da experiência ou das conceptualizações supostamente infalíveis (ou simplesmente transitivas) sobre o real. Então, para eliminar a tese idealista, mas consequentemente relativista, de que esse est percipi ("o ser é ser percebido", usando as palavras de Berkeley, 2010, p. 59), Bhaskar (2004, p. xi) invoca o critério causal para se atribuir à realidade ou se atingir a dimensão intransitiva e reafirmar a ontologia do real, sugerindo fortemente um realismo vertical, em que a ciência poderia ser vista como sendo "um processo contínuo e reiterado de movimentos que vão dos fenômenos manifestos [...] à identificação de suas causas gerativas".

\section{Questões ao realismo crítico transcendental em ADC}

Esse critério causal que esboçamos acima nos permite fazer outra observação. A causação bhaskariana não é do tipo mecânico ou de "conjunções constantes entre causas e efeitos", tal como é alegado por Bhaskar em referência a David Hume. Bhaskar se opõe a essa visão de Hume, já que este não seria capaz de diferenciar uma correlação causal de uma acidental entre dois eventos (cf. BHASKAR, 2008; HAMLIN, 2000, p. 4). Por isso, Bhaskar entende a dimensão ontológica da realidade como um sistema aberto, e não fechado, em que as estruturas, mecanismos ou poderes gerativos de outros sistemas (semiótico, biológico, físico etc.) influenciam em um evento. A conexão entre uma causa e um efeito não necessariamente provirá de conjunções constantes entre ambas, pois que há outros estratos que codeterminariam e alterariam a realização ('actuality') de um evento, ou seja, os efeitos. ${ }^{5}$

\footnotetext{
${ }^{5}$ Ressaltamos que tal pressuposto de um mundo aberto, composto por vários estratos, ou de que a linguagem, semiose, é apenas um entre outros elementos que participam de um evento e que poderiam ser analisados, encontra-se também na ADC de Fairclough (cf. capítulo 2 de CHOULIARAKI; FAIRCLOUGH, 1999, p. 20), principalmente em
} 
Contudo, o que parece escapar da própria crítica de Bhaskar à discussão da causalidade humeana é a ideia de que, em Hume (2004, 2009), a causa é, antes, o resultado de uma projeção humana sobre a experiência, e não algo natural, como se participasse aprioristicamente da formação de eventos e fatos da experiência. Como argumenta Cesar Kiraly (2012), em Hume, a causalidade é um artifício da natureza humana que compõe a experiência em termos tais que possibilitam "nos sentir em casa" na experiência, além do que nos faz imaginar ter uma chance de prever o futuro, pela conjunção, atribuidamente constante, de fatores (causas) que o sujeito cognoscente lança sobre a experiência. Embora Hume seja ainda adepto de uma discussão acerca da natureza humana, o que lhe faz pensar em algo que constitui a natureza do sujeito (discussão essa digna de seu tempo), o que ele nos fornece como possibilidade de se pensar o conhecimento na sua relação com o sujeito é a compreensão de que o sujeito se habitua à experiência por meio do estabelecimento de mecanismos causais sobre o mundo que lhe fazem inventar a experiência que lhe constitui (KIRALY, 2012). ${ }^{6}$

Dessa forma, Hume, ao lançar com sua filosofia a constituição da experiência nas projeções que o sujeito faz em sua cotidianidade, fornece, antes, uma compreensão negada por Bhaskar, ${ }^{7}$ mas retomada, em alguma medida, pela "virada pragmática" no campo da filosofia

sua afirmação de que uma prática social possui outros elementos que não apenas a linguagem, que poderia internalizá-los ou não: "[...] we recognise that words can be 'mere' or 'empty' words (as we think they can), we can see this in terms of an absence of internalization - a divorce for instance between the ways in which people act and the ways in which they discursively construct their actions, the former not internalizing the latter" (CHOULIARAKI; FAIRCLOUGH, 1999, p. 28, grifo nosso).

${ }^{6} \mathrm{Cf}$. também um dos primeiros estudos monográficos de Gilles Deleuze (2012), Empirismo e Subjetividade, sobre David Hume, em que trata os princípios de causalidade, associação e contiguidade como estabelecendo relações entre dados da experiência as quais, embora exteriores aos dados relacionados, dão a impressão de ultrapassar a própria experiência do dado.

${ }^{7}$ Como Bhaskar defende (2008), assim como Chouliaraki e Fairclough (1999) e Fairclough (2003), a vida social não é composta exclusivamente pelo estrato semiótico no qual se encontra a linguagem-, já que com este outros estratos interagem na geração de eventos e efeitos que complexificam a vida social, mas não lhe impossibilitam o conhecimento, cabendo, assim, às ciências a tarefa de progredir em investigações que acenem com uma compreensão cada vez mais profunda do real. 
analítica: a ideia de que a linguagem é uma forma de vida pela qual nos é dada a possibilidade de constituir, de performativizar a experiência (cf. WITTGENSTEIN, 1999; AUSTIN, 1990, 1975; OTTONI, 1998). Essa compreensão pragmática da linguagem e da experiência, portanto, nos impede, em certa medida, de compactuar com a ideia de um "progresso científico" que se valida pelo estabelecimento e reconhecimento cada vez mais complexo, amplo e eficaz de conexões causais geradoras de eventos sociais, já que a forma como projetamos explicações sobre o mundo passa necessariamente pela linguagem. Bhaskar (2004, 2005, 2008), Chouliaraki e Fairclough (1999) e Fairclough (2003) manifestam, com tal postura epistemológica, um "medo da morte" (ALENCAR, 2009) no trabalho com a linguagem, por desalojarem dela o caráter compulsório que possui para conosco no trato com um mundo social que ela mesma nos faz constituir.

Dessa forma, surge outra questão: em que sentido é possível separar uma prática social em que o discurso, a linguagem, participa, internalizando outros elementos, e uma prática social em que a linguagem não estaria a eles articulada? Em outras palavras, até que ponto é metodológica e epistemologicamente adequado acreditar, mesmo que analiticamente, numa ação que pode ser linguística, discursiva, e numa ação não linguística? Tais questões surgem em contraposição a uma compreensão de linguagem como elemento não apenas indissociável da vida social, mas principalmente compulsório, como vemos em Wittgenstein (1999) e Austin (1990; 1975), sem a qual não é possível pensar qualquer relação entre elementos alegadamente não linguísticos. Eis uma compreensão que se faz útil e indispensável na prática analítica da Linguística Aplicada.

Além disso, como ainda acima argumentamos, escapa desse entendimento sobre a causação bhaskariana uma ideia bem humeana, como a vemos em Jürgen Habermas, de que "supomos [um] mundo objetivo como sistema para referências possíveis - como o conjunto de objetos, não de fatos" (HABERMAS, 2004, p. 35, ênfase nossa). Contudo, Bhaskar (2005, 2008, 2009; ARCHER, 2004; COLLIER, 1994) prefere partir da ideia de que a realidade é estratificada, e cada estrato pode causar efeitos em outros, deixando de lado a possibilidade de pensar a realidade como um mundo suposto de referências possíveis. Graças a esse poder causal ou poder gerativo, poderíamos, na perspectiva realista crítica, chegar a uma dimensão intransitiva dos eventos, em que 
os mecanismos causais teriam sido desvendados e descritos. Assim, a tarefa explanatória desse tipo de filosofia e da ADC reside em explicar, da forma mais adequada possível, eventos com base na identificação dos mecanismos causais que a eles mais profundamente subjazem e geram, o que reforça a crença em um mundo real, objetivo com referências, objetos fixos que podemos revelar cientificamente.

\section{Quo vadis?}

Cremos que o grande desafio de qualquer trabalho analítico é não conciliar seus resultados com o estabelecimento de uma nova verdade (não quero dizer que devamos, contudo, aceitar alguma possivelmente existente), embora seja, em certa medida, essa conciliação (mas com devidas considerações no que concerne ao termo "verdade") que torna academicamente digno de ser executado um trabalho analítico; e nisso está presente a perspectiva emancipatória, tanto reivindicada para a ADC (cf., CHOULIARAKI; FAIRCLOUGH, 1999; FAIRCLOUGH, 2003; RAMALHO, 2009; RESENDE, 2009; SAYER, 2000). De fato, a pesquisa social tem de ser emancipatória, ou melhor dizendo, interventora; mas interventora não como um juiz, árbitro, ou como se fosse um desbravar de selvas e matas em busca do real (dos mecanismos causais). Interventora, mas sempre política, cujo discurso resultante de uma pesquisa seja uma proposta para o domínio analisado e para novas relações sociais nele presentes.

O problema da falibilidade do $\mathrm{RC}$, no estabelecimento de uma explicação da realidade, parece resgatar uma crença de que os poderes causais podem ser esgotados cumulativamente pelo acréscimo de novas informações ou descobertas de abordagens que denunciem mais clara e profundamente possível a natureza das coisas. O uso de critérios causais para a explicação dos fenômenos realizados ('actualized') estabelece a compreensão de que os poderes causais da realidade, embora nem sempre se manifestem, definem sua própria natureza, pelo que se afirma que haverá uma relação real entre os acontecimentos de causa e efeito, ligando-os naturalmente, mesmo que tal ligação esteja acima de nossa experiência (Cf. BHASKAR, 2008, p. 29-30; HALFPENNY, 1996). Desse modo, a atividade científica ou tarefa explanatória da pesquisa social orientada pelos princípios do RC é um movimento do empírico (que vai se purificando, na investigação, dos valores, da história, da falibilidade de um momento social) ao real - ontologia purificada das 
contingências (cf. o texto de RAMALHO, 2009, para a confirmação desse tipo de atitude científica na tarefa da pesquisa social baseada no RC).

A defesa da afirmação de uma dimensão intransitiva do conhecimento, fundamentada na crença de um, digamos assim, grau zero do mundo social - o "real", em termos do RC - pode desembocar, quando de sua operacionalização na ADC (CHOULIARAKI; FAIRCLOUGH, 1999; FAIRCLOUGH, 2003), numa reificação (sistemática) dos usos sociais da linguagem. Esse é um ponto muito delicado, sobretudo para pesquisas em Linguística Aplicada que usam a ADC como ponto de partida teórico, analítico e metodológico, pois tal pressuposição pode levar a um posicionamento em relação ao texto, discurso, de desvelamento, como se a linguagem participasse de um evento sócio-discursivo para esconder uma possível realidade "por trás" ou "além" da "aparência textual". Além disso, o pressuposto que subjaz essa crença comporta uma visão essencialista de mundo e de linguagem, muito diferente daquela que procuramos advogar neste artigo, baseada em Wittgenstein (1999) e Austin (1990, 1975). Essa visão essencialista do mundo e da linguagem nos faz partilhar da posição, problemática, de que há uma realidade por trás dos fenômenos discursivos que engendra nosso uso da linguagem, realidade essa a que podemos chegar por meio de uma análise que não seja só linguística mas também social.

Além disso, tal visão acena com a possibilidade de um acesso privilegiado ao que se crê ser uma realidade, desalojando-nos da responsabilidade de sermos nós, antes, atores sociais que encenam e performatizam, em vez de simplesmente representarem como os seus tradutores fieis e literais, uma realidade. Uma visão antiessencialista e performativa da linguagem, pelo contrário, coloca em nosso colo (sejamos nós um dito "leigo" ou um dito "cientista") a responsabilidade e consciência de que o que fazemos quando dizemos algo é parte indissociável de uma construção inescapavelmente social da realidade.

Não obstante, não afirmamos, em relação ao $\mathrm{RC}$ e à $\mathrm{ADC}$, que o sistema semiótico é fechado, que ele tenha mecanismos causais que estejam desvinculados de conexões com os de outros estratos, nem que ele independa do processo de construção dos sentidos em que se envolvem posicionamento social, conhecimentos, experiências e crenças do interlocutor, o que resulta sempre em compreensões, interpretações, construções particulares. A questão principal está em reconsiderar se mesmo a análise textual não concedendo uma análise definitiva de um 
texto ou evento social textualmente mediado - é possível chegar, por meio das construções dos agentes, criticamente às causas subjacentes de um evento (que podem ser uma confluência de poderes causais de vários estratos, que não só o semiótico), ou seja, é reavaliar o fato de que o discurso, enquanto semiose, tem seus poderes causais, que seriam o "real", na perspectiva realista crítica.

É essa, por exemplo, a defesa de Fairclough, Jessop e Sayer (2002, p. 3), pois, segundo eles, se alguém pergunta o caminho para se chegar a um lugar e as respostas podem ser "dobrando a esquina", "Desculpeme, mas não sei" ou "Por que você quer saber?", a relação pergunta / resposta depende do contexto, mas a resposta é ao menos coproduzida pela pergunta em si. O problema disso pode estar na crença de que a compreensão e explanação do funcionamento dos mecanismos gerativos vão se constituir em um nível mais profundo da realidade dos eventos ou dos problemas que, na prática, sustentam relações de poder assimétricas (como é um dos focos na pesquisa social feita na ADC). É daí que vem a visão de que a ADC é desmistificadora e emancipatória. Contudo, o que se perde de vista é a confusão (rechaçada pela compreensão de que seria uma "falácia epistêmica") que fazem os pesquisadores em geral que tomam por base os pressupostos do RC, ao acreditarem que a percepção causal dos eventos discursivos (seus mecanismos gerativos e poderes causais) é a realidade intransitiva (o fato de que as coisas existem independentemente da concepção que tenhamos sobre elas, a qual é sempre contingente e que é o único meio que dispomos para conhecer o mundo) ou que a ontologia do real não seria uma epistemologia 'actual', para usarmos aqui os termos do RC.

Ao assumir um ponto de vista performativo e antiessencialista da linguagem em análises do discurso, acreditamos que nos aproximaríamos daquilo que hoje a Linguística Aplicada nos faz compreender: aquilo que o analista faz também é linguagem, portanto performatização do real. Assim, o que quer que seja a compreensão e explanação que tenhamos acerca dos fenômenos sociais, até mesmo das conexões causais, ainda que se ressalte o entendimento da natureza aberta dos sistemas que compõem o mundo da vida (o que se complexaria ainda mais chegarmos aos poderes gerativos dos eventos), teremos sempre um discurso, com seus valores sociais, políticos e ideológicos. Isso nos leva à compreensão de Horkheimer acerca da ciência tradicional: 
As regras da experiência [...] não são outra coisa que formulações do nosso saber a respeito dos [possíveis] nexos econômicos, sociais e psicológicos. [...] Tanto a fecundidade de nexos efetivos recém-descobertos para a modificação da forma do conhecimento existente, como a aplicação deste conhecimento aos fatos são determinações que não têm origem em elementos puramente lógicos ou metodológicos, mas só podem ser compreendidos em conexão com os processos sociais reais (HORKHEIMER, 1989, p. 35, grifo nosso).

Uma vez assumindo que sua abordagem se enquadra na tradição da ciência social crítica, que é motivada pelo objetivo de fornecer base científica para o questionamento crítico da vida social, ao adotarem os princípios do realismo transcendental da filosofia de Roy Bhaskar, as análises críticas do discurso amenizam a compreensão do papel mundano e politicamente enraizado do pesquisador social crítico, como tentativa de escapar da ideia de um "infinito jogo de diferença” (DERRIDA, 1995), de um imperialismo discursivo ou um socioconstrutivismo extremo. $\mathrm{O}$ que o enquadre ontológico e epistemológico do realismo crítico de Bhaskar fornece à ADC, mas que parece ignorar, assim, ao defender as dimensões transitiva e intransitiva do conhecimento, é que, qualquer que seja a compreensão dos "poderes causais", ela será sempre discursiva, isto é, uma pretensão de verdade, que necessita de validação e justificação (HABERMAS, 2004) via linguagem, discurso e argumentação.

Não queremos dizer com isso que "tudo é discurso", mas, sim, que o entendimento de tais poderes não coincidiria com camadas profundas de uma realidade, pois, se esta existe independentemente do nosso conhecimento acerca dela, sua compreensão passa a se configurar como uma construção social e contingente dos próprios eventos no mundo por se dar via linguagem. Portanto, as análises críticas do discurso, por estarem respaldadas por princípios do RC de Roy Bhaskar, parecem escapar do problema da justificação das pretensões de verdade, ignorando uma compreensão, como a de Habermas (2004, p. 35), de que:

[...] não faz sentido orientar a validade de juízos pela diferença entre ser e parecer, entre o dado 'em si' e o dado 'para nós' - como se o conhecimento do pretensamente imediato devesse ser purificado de ingredientes subjetivos e mediações intersubjetivas. [...] Do ponto de vista 
pragmático, a realidade não é algo a ser retratado; ela não se faz notar senão performativamente, pelas limitações a que estão submetidas nossas soluções de problemas e nossos processos de aprendizado - ou seja, como a totalidade das resistências processadas e das previstas.

Isso não significa que descartamos terminantemente a $\mathrm{ADC}$ como alternativa viável e eficaz para análises de discurso. Conforme falamos, os problemas que identificamos em seu enquadre se relacionam ao seu consórcio com princípios realistas críticos, sobretudo a partir da obra de Chouliaraki e Fairclough (1999), retomada em Fairclough (2003). A adoção das premissas do RC via ADC é que reduz qualquer perspectiva que acene com certa simpatia para um antiessencialismo ou socioconstrutivismo em linguagem. Chouliaraki e Fairclough até mesmo se defendem contra teorias pós-estruturalistas com receio de uma "tirania" do discurso e de uma abertura sem precedentes do social a qualquer análise exclusivamente linguístico-semiótica (cf. capítulo 7, de CHOULIARAKI; FAIRCLOUGH, 1999, p. 120).

Portanto, nossa defesa aqui é percorrer outra trilha, menos comprometida com o viés ontológico e epistemológico tal qual o do $\mathrm{RC}$, operacionalizado na perspectiva cientista de pesquisa social da ADC, de modo a estimular que pesquisadores e pesquisas em Linguística Aplicada (que usam a $\mathrm{ADC}$ como enquadre teórico, analítico e metodológico) estejam mais empenhados em assumir responsabilidades éticas e políticas provenientes da prática analítica a que submetem seus objetos de estudo e a que se submetem eles próprios. Esta trilha pode ser encontrada em trabalhos na filosofia da linguagem que, em vez de se comprometer com proposições ontológicas a respeito do que é ou pode ser o mundo (inclusive determinando o que é linguístico e o que não é), parte para uma consideração dos efeitos que socialmente constituem realidades possíveis.

\section{Considerações finais}

Acreditamos que essa postura aqui advogada em favor de um compromisso, em análises do discurso, com uma concepção de linguagem enquanto ação compulsória de constituição do mundo e mundos possíveis - já acenada no quadro de discussões da Linguística Aplicada atual, concebida como crítica, indisciplinar e transdisciplinar (PENNYCOOK, 2001; MOITA LOPES, 2006) - possibilita pensarmos cada vez mais em 
uma perspectiva crítica nos estudos da linguagem que não desassocia nossa prática reflexiva e analítica de nossa própria participação no mundo social, o que nos leva a ver a pesquisa não como uma tarefa de especialistas que têm acesso privilegiado a um corpo de conhecimento e que, portanto, podem ser considerados como atores sociais unicamente autorizados a propor alternativas ao mundo social. Pelo contrário, adotar esta postura aqui defendida seria lançar o pesquisador no cotidiano, fazêlo participar cada vez mais de esferas públicas de debate em que tanto o dito leigo quanto o dito cientista partiriam do mesmo ponto comum para validar seus discursos - a argumentação-, e não da crença assimétrica de que um tem mais conhecimento científico, verdadeiro e, portanto, mais real do que outro.

\section{Referências}

ALENCAR. Linguagem e medo da morte: uma introdução à linguística integracionista. Fortaleza: EDUECE, 2009.

ARCHER, Margaret et al. (Ed.). Critical Realism: Essential Readings. London; New York: Routledge, 2004.

AUSTIN, John Langshaw. How to do things with words. Cambridge, Massachusetts: Harvard University Press, 1975.

- Quando dizer é fazer. Palavras e ação. Tradução de Danilo Marcondes de Souza Filho. Porto Alegre: Artes Médicas, 1990.

BERKELEY, George. Obras filosóficas. Tradução de Jaimir Conte. São Paulo: Editora da UNESP, 2001.

BHASKAR, Roy. Realismo. In: BOTTOMORE, Tom; OUTHWAITE, William. (Ed.). Dicionário do Pensamento Social do Século XX. Tradução de Álvaro Cabral e Eduardo Francisco Alves. Rio de Janeiro: Jorge Zahar Editor, 1996, p. 647-649.

. General Introduction. In: ARCHER, Margaret et al. (Ed.). Critical Realism: Essential Readings. London; New York: Routledge, 2004, p. ix-xxiv.

2005.

. The possibility of naturalism. London; New York: Routledge, . A realist theory of science. London: Verso, 2008. 
. Scientific Realism and Human Emancipation. London; New York: Routledge, 2009.

BLOMMAERT, Jan. Discourse. A critical introduction. Cambridge: Cambridge University Press, 2005.

CAMERON, Deborah et al. Researching Language: issues of power and method. London: Routledge, 1992.

CHOULIARAKI, Lilie; FAIRCLOUGH, Norman. Discourse in late modernity. Rethinking Critical Discourse Analysis. Edinburg: Edinburg University Press, 1999.

COLLIER, Andrew. Critical Realism: an introduction to Roy Bhaskar's philosophy. London: Verso, 1994.

DELEUZE, Gilles. Empirismo e Subjetividade. Ensaio sobre a natureza humana segundo Hume. Tradução de Luiz B. L. Orlandi. São Paulo: Editora 34, 2012.

DERRIDA, Jacques. A estrutura, o signo e o jogo no discurso das ciências humanas. In: . A escritura e a diferença. 2. ed. Tradução de Maria Beatriz Marques Nizza da Silva. São Paulo: Perspectiva, 1995, p. 229249.

FABRÍCIO, Branca Falabella. Lingüística aplicada como espaço de "desaprendizagem": redescrições em curso. In: MOITA LOPES, Luiz Paulo da (Org.). Por uma linguística aplicada indisciplinar. São Paulo: Parábola Editorial, 2006, p. 45-65.

FAIRCLOUGH, Norman. Discurso e mudança social. Tradução coordenada por Izabel Magalhães. Brasília: Editora UnB, 2001.

Analysing discourse. Textual analysis for social research. London: Routledge, 2003.

FAIRCLOUGH, Norman; JESSOP, Bob; SAYER, Andrew. Critical Realism and Semiosis. Department of Sociology, Lancaster University, 2002, p. 1-14. Disponível em: <http://www.lancs.ac.uk/fass/sociology/ papers/fairclough-jessop-sayer-critical-realism-and-semiosis.pdf $>$. Acesso em: 24 jun. 2014.

FREGE, Gottlob. Sobre o sentido e a referência. In: . Lógica e filosofia da Linguagem. Tradução de Paulo Alcoforado. São Paulo: Cultrix, 1978, p. 59-86. 
HABERMAS, Jürgen. Verdade e Justificação. Ensaios Filosóficos. Tradução de Milton Camargo Mota. São Paulo: Edições Loyola, 2004.

HALFPENNY, Peter. Explicação. In: BOTTOMORE, Tom; OUTHWAITE, William. (Ed.). Dicionário do Pensamento Social do Século XX. Tradução de Álvaro Cabral e Eduardo Francisco Alves. Rio de Janeiro, Jorge Zahar Editor, 1996, p. 294-295.

HAMLIN, Cynthia Lins. Realismo Crítico: Um Programa de Pesquisa para as Ciências Sociais. In: Dados - Revista de Ciências Sociais. Ano/ vol. 43, número 2. Instituto Universitário de Pesquisas do Rio de Janeiro, 2000. Disponível em: <http://redalyc.uaemex.mx/pdf/218/21843206. pdf $>$. Acesso em: 24 jun. 2014.

HORKHEIMER, Max. Teoria Tradicional e Teoria Crítica. In: HORKHEIMER, Max; ADORNO, Theodor W. Textos Escolhidos. Tradução de Edgard Afonso Malagodi e Ronaldo Pereira Cunha. São Paulo: Nova Cultural, 1989, p. 31-68.

HUME, David. Investigações sobre o Entendimento Humano e sobre os Princípios da Moral. Tradução de José Oscar de Almeida Marques. São Paulo: Editora UNESP, 2004.

. Tratado da Natureza Humana. Tradução de Déborah Danowski. 2. ed. São Paulo: Editora UNESP, 2009.

KIRALY, Cesar. A Outra Modernidade de Hume. In: Breviário de Filosofia Pública, L(E)H - Laboratório Estudos Hum(e)anos, UFF, n ${ }^{\circ}$ 66, 06/2012, p. 198-200, 2012.

MOITA LOPES, Luiz Paulo da (Org.). Por uma Linguística Aplicada indisciplinar. São Paulo: Parábola Editorial, 2006.

OLIVEIRA, Manfredo Araújo de. Reviravolta lingüistico-pragmática na filosofia contemporânea. São Paulo: Edições Loyola, 2006.

OTTONI, Paulo. Visão performativa da linguagem. Campinas: Editora da Unicamp, 1998.

PENNYCOOK, Alastair. Critical Applied Linguistics: a critical introduction. Mahwah: Lawrence Erlbaum, 2001.

RAMALHO, Viviane. Análise de Discurso e Realismo Crítico: princípios para uma abordagem crítica explanatória do discurso. In: CONFERÊNCIA ANUAL DA IACR - INTERNATIONAL ASSOCIATION FOR 
CRITICAL REALISM, 12., 2009, Niterói. Anais da XII Conferência Anual da IACR - International Association for Critical Realism. Realismo e emancipação humana. Um outro mundo é possível?. Universidade Federal Fluminense (UFF), Niterói/RJ, 2009.

RESENDE, Viviane de Melo. Análise de discurso crítica e realismo crítico: implicações interdisciplinares. Campinas: Pontes Editores, 2009. RORTY, Richard (Ed.).The Linguistic Turn: Essays in Philosophical Method (with tow retrospective essays). Chicago: University Of Chicago Press, 1992.

SAYER, Andrew. Características-chave do Realismo Crítico na prática: um breve resumo, Estudos de Sociologia. Revista do Programa de PósGraduação em Sociologia da UFPE, v.6, n. 2, p. 7-32, 2000.

WITTGENSTEIN, Ludwig. Investigações filosóficas. Tradução de José Carlos Bruni. São Paulo: Editora Nova Cultural, 1999. 
